\title{
Computer-aided identification of the water diffusion coefficient for maize kernels dried in a thin layer**
}

\author{
Sebastian Kujawa ${ }^{1}$, Jerzy Weres ${ }^{1 *}$, and Wiesław Olek ${ }^{2}$ \\ ${ }^{1}$ Faculty of Agriculture and Bioengineering, Institute of Biosystems Engineering, \\ ${ }^{2}$ Faculty of Wood Technology, Department of Mechanical Engineering and Thermal Techniques, \\ Poznań University of Life Sciences, Wojska Polskiego 28, 60-637 Poznań, Poland
}

Received October 10, 2015; accepted July 12, 2016

\begin{abstract}
A b s t r a c t. Uncertainties in mathematical modelling of water transport in cereal grain kernels during drying and storage are mainly due to implementing unreliable values of the water diffusion coefficient and simplifying the geometry of kernels. In the present study an attempt was made to reduce the uncertainties by developing a method for computer-aided identification of the water diffusion coefficient and more accurate 3D geometry modelling for individual kernels using original inverse finite element algorithms. The approach was exemplified by identifying the water diffusion coefficient for maize kernels subjected to drying. On the basis of the developed method, values of the water diffusion coefficient were estimated, 3D geometry of a maize kernel was represented by isoparametric finite elements, and the moisture content inside maize kernels dried in a thin layer was predicted. Validation of the results against experimental data showed significantly lower error values than in the case of results obtained for the water diffusion coefficient values available in the literature.

K e y w o r d s: maize kernels, inverse finite element modelling, water diffusion coefficient
\end{abstract}

\section{INTRODUCTION}

High moisture content and relatively high temperature of harvested maize kernels increase negative biological processes deteriorating their quality. Therefore, maize should be properly preserved after harvesting (Suleiman et al., 2013). Computer simulation is helpful in designing such operations - it enables users to quickly assess various options of the drying and storing processes. However, satisfactory simulation results can only be achieved when based on a mathematical model supplemented by appropriate,

*Corresponding author e-mail: weres@up.poznan.pl

**This work was financially supported by the National Science Centre of Poland under the research grant No. 2011/01/B/ NZ9/03169. adequate and reliable values of physical properties of the investigated system (Erbay and Icier, 2010; Olek et al., 2011). In analysing the maize kernel drying processes the falling-rate period is often assumed as the only period, and the internal diffusion of water plays a dominant role in the drying process. The movement of water inside kernels is complex and it can occur simultaneously in the liquid and gas phases. Therefore, the effective water diffusion coefficient used for mathematical modelling is responsible for representing the rate of total water removal from the interior of the kernel (Kumar et al., 2012). Unfortunately, values of the water diffusion coefficient in maize kernels reported in the literature differ from each other (Chen et al., 2009; Doymaz and Pala, 2003; Kumar et al., 2012; Muthukumarappan and Gunasekaran, 2009; Pabis et al., 1998). Simplification of the kernel geometry and the diffusion model type are the main reasons for such differences (Kumar et al., 2012; Weres et al., 2014a). For example, the value of the water diffusion coefficient obtained for a rectangular shape of the kernel was more than three times greater than for a spherical shape at the same temperature and relative humidity of drying air (Syarief et al., 1984; Pabis et al., 1998).

Many studies have been performed in the area of developing mathematical structural models describing cereal grain drying processes. Most of the models contain distinct submodels for drying grains in thin layers (Hacihafizoglu et al., 2011; Kumar et al., 2012; Muthukumarappan and Gunasekaran, 2009; Nemenyi et al., 2000; Pabis et al.,

(C) 2016 Institute of Agrophysics, Polish Academy of Sciences 
1998). One of such structural submodels was developed in a numerical operational form (Weres and Jayas, 1994). Although it manifests much lower uncertainty of predictions compared to other, more simplified models, it requires further improvement of its predictive capability by more relevant representation of the process parameters. So far, dubious values of the water diffusion coefficient available in the literature have been used in mathematical models. Therefore, a coefficient inverse problem approach was proposed in this work to identify the water diffusion coefficient in maize kernels dried in thin layers.

The objectives of this study were:

- to develop a method for computer-aided identification of the water diffusion coefficient in maize kernels dried in a thin layer, based on laboratory measurements, and original finite element inverse analysis adequate for water transport in the selected biomaterial;

- to estimate values of the water diffusion coefficient on the basis of the developed method and, next, to use the estimated values to predict more reliable moisture content distributions inside maize kernels during the whole process of thin-layer drying.

\section{MATERIAL AND METHODS}

To identify the water diffusion coefficient in individual maize kernels, information was required on the moisture content changes during the thin layer drying of this material. Drying data were collected for maize kernels of the Clarica variety (FAO 280), produced by Pioneer, as the experimental material. The maize was grown at the Research and Education Centre Gorzyn of the Poznań University of Life Sciences in Poland. The material was manually cleared, packed in sealed plastic bags and placed in the refrigerator immediately after harvesting.

The method for the identification of the water diffusion coefficient in maize kernels comprised two stages: laboratory experiments and computer analysis. Experimental results were obtained and prepared as an input for the computer-aided identification of the water diffusion coefficient.

During the experiments the drying air temperature was $40^{\circ} \mathrm{C}$ and the relative humidity of drying air was 30 and $40 \%$. For each of the relative humidity values three replications of the experimental procedure were performed. The duration of each replication was $24 \mathrm{~h}$. During this period, the sample mass measurements were carried out automatically in time intervals of $5 \mathrm{~min}$.

In the computer analysis the three-dimensional irregular geometry of maize kernels was implemented, and a possibility to select between kernel non-homogeneity and homogeneity, with respect to the kernel components, was offered in the software. The initial condition was in the form of moisture content uniform distribution inside maize kernels, and it was possible to select between the first kind boundary condition, in which the kernel surface attains the equilibrium moisture content immediately after the start of drying, and the third kind boundary condition, in which the convective mass transfer coefficient in the boundary layer is taken into consideration. In addition, the computer analysis included:

- generalization of experimental data of the moisture content by an empirical formula as a function of drying time (Akpinar et al., 2003; Babalis et al., 2006; Weres and Jayas, 1994):

$$
M(\tau)=A \exp (-K \tau)+\left(M_{0}-A\right) \exp (-K B \tau),
$$

where: $\tau$ is time, $M_{0}$ is the initial moisture content and $A$, $\mathrm{B}$ and $K$ are the empirical formula parameters to be identified. - influence of the moisture content on the water diffusion coefficient for the temperature of $40^{\circ} \mathrm{C}$ expressed by the following empirical formulas:

variant I (Syarief et al., 1984):

$$
D_{m}(M)=a_{0} \exp \left(b_{0} M\right),
$$

where: $a_{0}$ and $b_{0}$ are the empirical formula parameters to be identified;

variant II (Jaros et al., 1992):

$$
D_{m}(M)=a_{1} M^{b_{1}} \exp \left(c_{1} M\right),
$$

where: $a_{1}, b_{1}$ and $c_{1}$ are the empirical formula parameters to be identified.

Before starting the experimental procedures, the initial mass of a sample of maize kernels was determined based on the assumption that experimental results should be characterised by low values of errors resulting from the uncertainty of the measuring instruments. To determine the minimal initial mass of a sample of kernels the relation given by Jaros (1994) was used:

$$
\begin{gathered}
W_{0}>\frac{1-\frac{M}{1+M}}{\delta_{z}\left(\frac{M}{1+M}-\frac{M_{0} M}{\left(1+M_{0}\right)(1+M)}\right)} \\
{\left[|\Delta W(\tau)|+\frac{1}{1-\frac{M}{1+M}}\left|\Delta W_{d}\right|\right],}
\end{gathered}
$$

where: $\delta_{\mathrm{z}}$ is the maximum permissible relative error of the moisture content determination, $\Delta W$ is the uncertainty of the measurement of the mass of a sample and $\Delta W_{d}$ is uncertainty of the measurement of the mass of sample dry matter.

The maximum permissible relative error of the moisture content determination $\delta_{z}$ was assumed at the level of $0.2 \%$. A Radwag WPE 300 electronic balance was used to 
measure the sample mass during drying; its uncertainty $\Delta W$ was at the level of $0.01 \mathrm{~g}$. The uncertainty of the Sartorius Basic BA 210S balance used to measure the mass of sample dry matter $\Delta W_{d}$ was $0.0001 \mathrm{~g}$. Before performing the experiments, the precise value of the initial moisture content for kernels was unknown. On the basis of preliminary measurements shortly after the harvest, it was assumed that the initial moisture content $M_{0}$ would be no higher than $0.429 \mathrm{~kg}_{\text {water }} \mathrm{kg}_{\text {d.m. }}{ }^{-1}$ at air relative humidity of $30 \%$. It was also assumed that the drying process would be conducted to achieve a value of the moisture content not less than the equilibrium moisture content for the lowest value of the relative humidity of drying air (30\%). The modified Chung-Pfost sorption isotherm equation with parameters for yellow dent maize was used to determine the equilibrium moisture content (ASABE, 2009a; Pabis et al., 1998):

$$
E M C=E-F \ln [-(t+C) \ln (0.01 R H)],
$$

where: $t$ is the temperature, and values of the parameters $C$, $E, F$ for the yellow-dent maize are 30.205, 0.339 and 0.059, respectively.

The equilibrium moisture content for drying air temperature of $40^{\circ} \mathrm{C}$ and relative humidity of $30 \%$ was $0.077 \mathrm{~kg}_{\text {water }} \mathrm{kg}_{\text {d.m. }}{ }^{-1}$. On the basis of the findings, the initial mass of a sample was determined using the initial moisture content of $0.429 \mathrm{~kg}_{\text {water }} \mathrm{kg}_{\text {d.m. }}{ }^{-1}$ and the final moisture content of $0.077 \mathrm{~kg}_{\text {water }} \mathrm{kg}_{\text {d.m. }}{ }^{-1}$. It was calculated from Eq. (4), supplemented by assumed values of its parameters, that the minimal initial mass of a sample of kernels should be higher than $93.62 \mathrm{~g}$. The relation between the minimal initial mass of a sample and the moisture content of kernels for the assumed value of the maximum permissible relative error of the moisture content determination, known uncertainty of the measuring instruments and the assumed values of

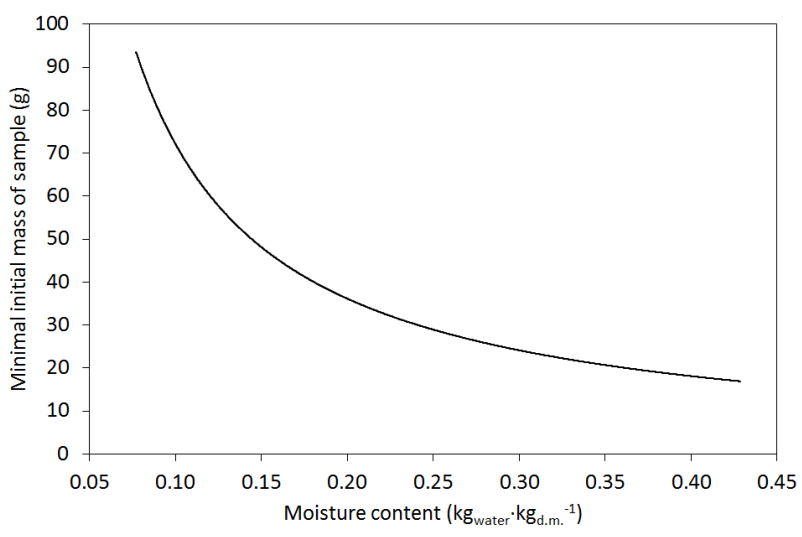

Fig. 1. The relation between the minimal initial mass of a sample and the moisture content of kernels $\left(\delta_{z}=0.2 \%, M_{0}=0.43 \mathrm{~kg}_{\text {water }}\right.$ $\left.\mathrm{kg}_{\text {d.m. }}{ }^{-1}\right)$. the initial and final moisture content, is presented in Fig. 1. Finally, taking into account an extra margin, the initial mass of a sample was set to $100 \pm 0.25 \mathrm{~g}$.

A test stand was set up to carry out the drying experiments. For obtaining and maintaining drying air temperature and relative humidity values at a desired level a computer-controlled climate chamber of $239 \mathrm{dm}^{3}$ was used. A sample of maize kernels was placed inside the climate chamber on a perforated tray connected to the weighing mechanism of a laboratory balance (Radwag WPE 300). The balance was connected to a computer by serial interface RS232. Computer software enabled monitoring and controlling the laboratory balance operations, including periodic mass measurement of the product placed on the tray. For each replication of the experimental procedure, the mass of a dried sample was automatically measured and saved to a computer hard drive at the beginning of the process and after each $5 \mathrm{~min}$ interval. After the expiry of the drying time the mass of the sample dry matter was determined by the oven-dry method - a sample was dried in the air temperature of $103^{\circ} \mathrm{C}$ for $72 \mathrm{~h}$ (ASABE, 2009b) and a laboratory balance (Sartorius Basic BA 210S) was used to determine the mass.

After each replication, when the mass of a sample in each time step and the mass of sample dry matter were known, it was possible to calculate the moisture content in maize kernels.

The results of the experimental procedures were generalised by the empirical formula (Eq. (1)), taking into account averaged values of the initial moisture content $M_{0}$ of 0.347 and $0.335 \mathrm{~kg}_{\text {water }} \mathrm{kg}_{\text {d.m. }}{ }^{-1}$, and averaged values of the final moisture content of 0.119 and $0.127 \mathrm{~kg}_{\text {water }} \mathrm{kg}_{\mathrm{d} . \mathrm{m} .}{ }^{-1}$, respectively, for the relative humidity of drying air of $30 \%$ and $40 \%$. The generalisation was performed by the Identix/ IPS software developed by the authors (Weres et al., 2009, 2014b).

A structural mathematical model of maize kernel drying in a thin layer is given in the form of quasi-linear differential equations of heat conduction and water transfer with the initial and boundary conditions (Jia et al., 2000; Pabis et al., 1998; Perré and Turnner, 2007; Ranjan et al., 2001; Weres and Jayas, 1994). In the present study the numerical operational form of this model (Weres and Jayas, 1994) was used as the starting point for improvements with respect to efficiency and accuracy. It was constructed by the finite element approximation with the use of isoparametric, curvilinear, non-homogeneous three-dimensional elements and recurrence schemes in time, with iterative procedures to consider quasi-linearity of the problem. The coupling of the heat conduction and water transport equations was reduced and only the moisture content values were computed. Due to the conditions under which the drying process took place, the effect of the third kind boundary condition was negligible, and it could be assumed that the surface of kernels attained the equilibrium moisture content after the 


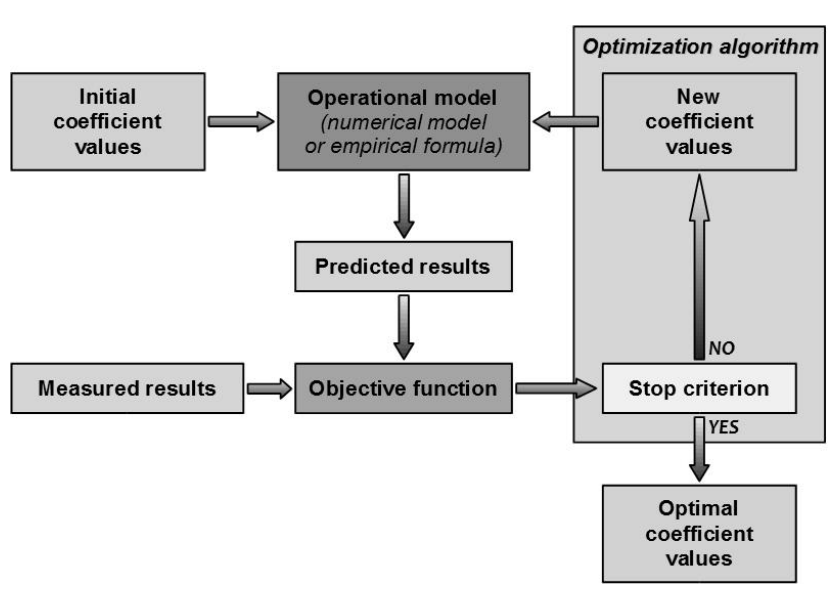

Fig. 2. The diagram of the identification algorithm.

start of the drying process. The model was supplemented with the modified Chung-Pfost Eq. (5) to determine the equilibrium moisture content.

The maize kernel shape was represented by an irregular geometry of three-dimensional, curvilinear, hexahedral, isoparametric finite elements (Weres and Jayas, 1994; Weres et al., 2014b). For computations, 480 elements and 693 nodes were automatically generated by the software developed by the authors, and 300 time-stepping intervals were used. The parameters used to approximate the problem in space and time can be easily changed from the input window. The effect of the moisture content on the water diffusion coefficient was taken into consideration according to empirical formulas (Eqs (2) and (3)), and the coefficient identification procedure comprised the estimation of parameters of these formulas $\left(a_{0}, b_{0}, a_{1}, b_{1}, c_{1}\right)$.

The diagram of the identification algorithm (Fig. 2) was based on the idea of solving inverse problems (Weres and Olek, 2005; Weres et al., 2009, 2014b). The objective function (Eq. (6)) was calculated as the sum of squared deviations between the measured and predicted average values of the moisture content in maize kernels for the investigated time intervals:

$$
S=\sum_{i=1}^{N T}\left[M_{e}\left(\tau_{i}\right)-M_{p}\left(\tau_{i}\right)\right]^{2} .
$$

The trust region method was used in the identification processes as the local optimisation algorithm with constraints (Weres et al., 2009). Validation of the numerical model filled with the estimated values of the water diffusion coefficient was performed by determining the local and the global relative errors of approximation (Weres and Jayas, 1994; Weres and Olek, 2005).

The computations were performed using the original software for determination and analysis of properties of agri-food and forest products (Weres et al., 2014b). The software comprises the discussed inverse finite element
T a b I e 1. Results for the empirical formula (Eq. (1)) for generalization of the experimental data of moisture content changes

\begin{tabular}{|c|c|c|c|c|}
\hline \multirow{2}{*}{$\begin{array}{l}\text { RH } \\
(\%)\end{array}$} & \multicolumn{3}{|c|}{ Parameters } & \multirow{2}{*}{$\begin{array}{l}\text { Global relative } \\
\text { error of } \\
\text { approximation } \\
(\%)\end{array}$} \\
\hline & A & B & $\mathrm{K}$ & \\
\hline 30 & 0.178 & 0.057 & 0.279 & 1.31 \\
\hline 40 & 0.163 & 0.052 & 0.260 & 1.16 \\
\hline
\end{tabular}

T a b l e 2. Results for the two-parameter empirical formula (Eq. (2)) for presentation of the water diffusion coefficient

\begin{tabular}{cccc}
\hline \multirow{2}{*}{ RH (\%) } & \multicolumn{2}{c}{ Parameters } & $\begin{array}{c}\text { Objective } \\
\text { function }\end{array}$ \\
\cline { 2 - 3 } & $\mathrm{a}_{0}$ & $\mathrm{~b}_{0}$ & 0.042 \\
\hline 30 & $1.19310^{-3}$ & $-1.06010^{0}$ & 0.033 \\
\hline
\end{tabular}

T a b l e 3. Results for the three-parameter empirical formula (Eq. (3)) for presentation of the water diffusion coefficient

\begin{tabular}{ccccc}
\hline RH & \multicolumn{3}{c}{ Parameters } & Objective \\
\cline { 2 - 5 }$(\%)$ & $\mathrm{a}_{1}$ & $\mathrm{~b}_{1}$ & $\mathrm{c}_{1}$ & \\
\hline 30 & $7.97610^{0}$ & $3.77810^{0}$ & $-1.45310^{1}$ & 0.031 \\
40 & $4.38310^{0}$ & $3.36810^{0}$ & $-1.44010^{1}$ & 0.027 \\
\hline
\end{tabular}

modelling and identification approach, with a possibility to select among algorithms and performance options appropriate for a given research.

\section{RESULTS}

The parameters of the empirical formula (Eq. (1)) obtained for the generalisation of the experimental data of moisture content changes for the relative humidity $(\mathrm{RH})$ of $30 \%$ and $40 \%$ are presented in Table 1 . This table also contains the values of uncertainty of the empirical formula (Eq. (1)) supplemented by obtained parameters, expressed as the global relative error of approximation.

The parameters of the two-parameter empirical formula (Eq. (2)) and also of the three-parameter empirical formula (Eq. (3)), which were the results of identifying the water diffusion coefficient, are presented in Tables 2 and 3 , respectively.

The relations between the estimated results of the water diffusion coefficient and the moisture content inside maize kernels for drying air temperature of $40^{\circ} \mathrm{C}$ and relative humidity of 30 and $40 \%$ are presented in Fig. 3 . The values 


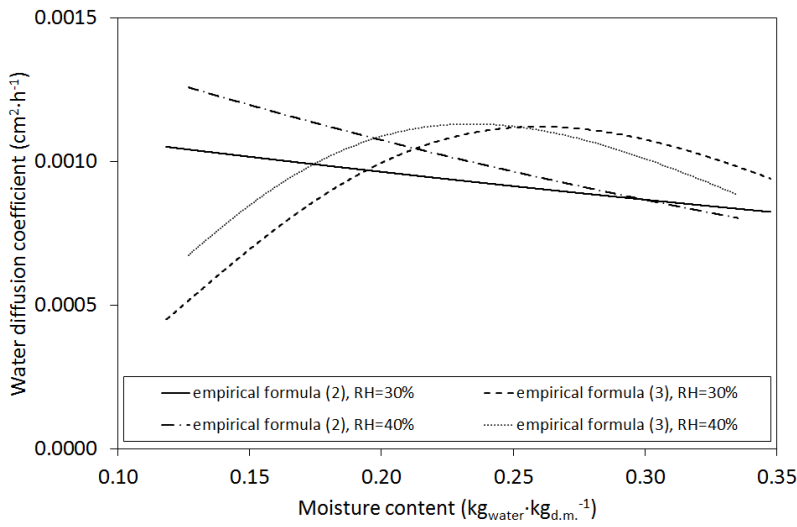

Fig. 3. The relation between the water diffusion coefficient and the moisture content inside corn kernels obtained for the drying air temperature of $40^{\circ} \mathrm{C}$ and the relative humidity of 30 and $40 \%$.

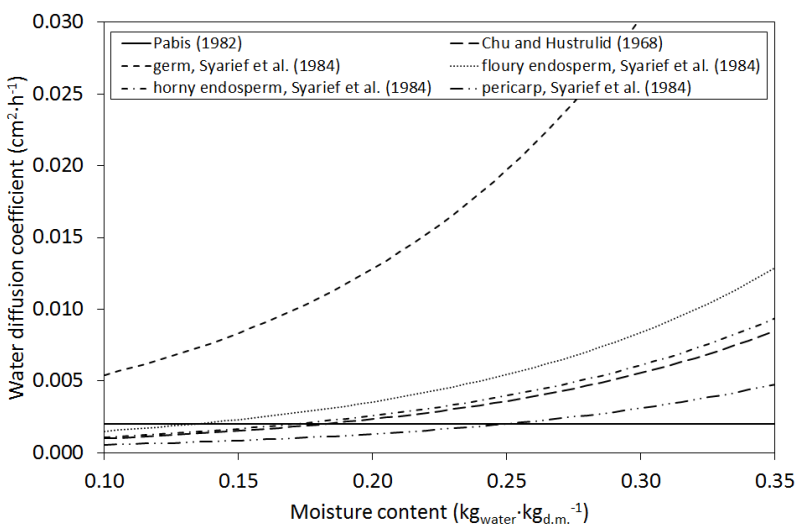

Fig. 4. The relation between the water diffusion coefficient and the moisture content inside corn kernels for the drying air temperature of $40^{\circ} \mathrm{C}$, simulations based on the literature data for the water diffusion coefficient.

of the water diffusion coefficient obtained using the empirical formula (Eq. (2)) are the lowest at the initial moisture content. During the drying process, these values increase with decreasing moisture content to reach a maximum at the final moisture content. Analysing the results obtained using the empirical formula (Eq. (3)) it can be observed that the water diffusion coefficient increases with decrease of the moisture content from its initial value until it reaches a certain value. Further decrease of the moisture content causes a lowering of the value of this coefficient.

The estimated values of the water diffusion coefficient were used in the numerical structural model to predict the moisture content inside maize kernels dried in a thin layer for $24 \mathrm{~h}$. Additionally, the literature values of the water diffusion coefficient were used in the predictions.

In total, five variants of computer simulations were performed. The simulation symbols and their meaning are given:
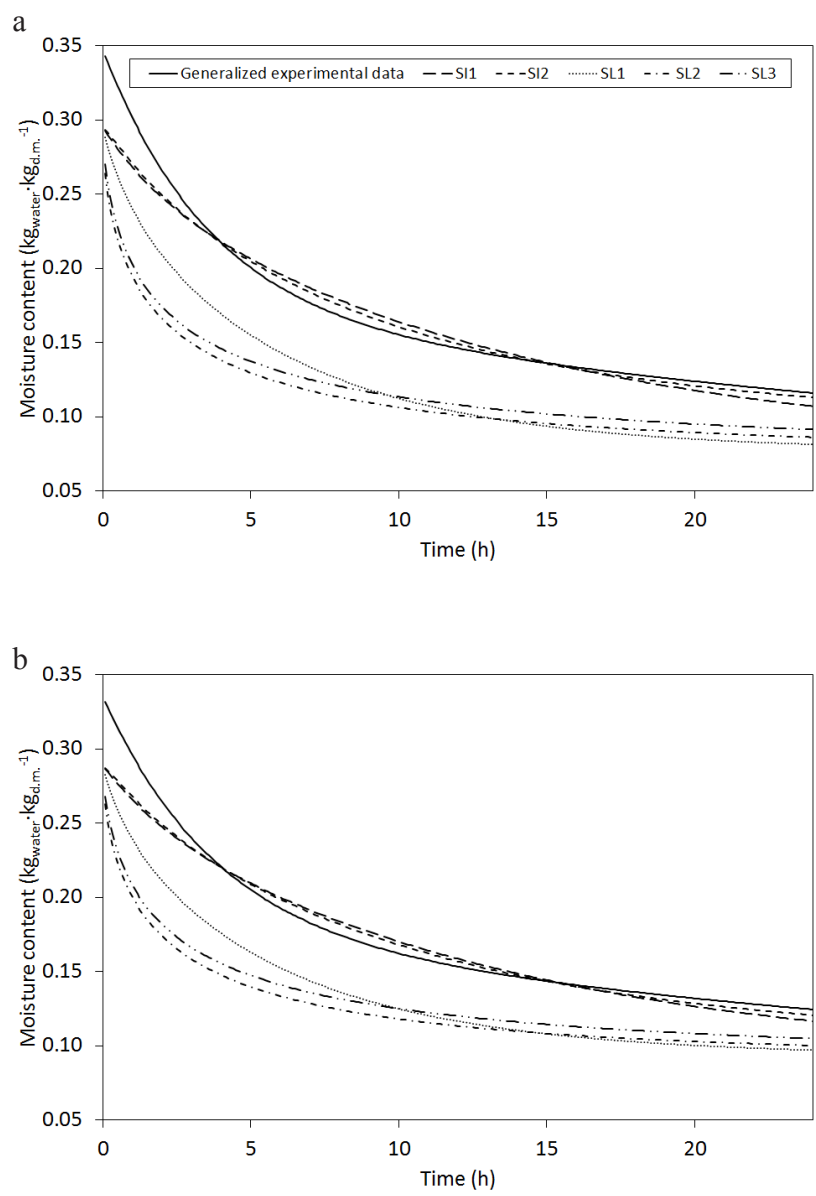

Fig. 5. Generalized experimental data and the predicted values of the moisture content inside corn kernels dried in a thin layer at the drying air temperature of $40^{\circ} \mathrm{C}$ and the relative humidity of: $a-30$ and $b-40 \%$.

SI1, SI2 - the water diffusion coefficient values were estimated from Eq. (2) and Eq. (3), respectively, and then used for the simulations.

SL1, SL2, SL3 - the water diffusion coefficient values were taken from the literature, and then used for the simulations (Fig. 4). In case of SL1 a constant value of the water diffusion coefficient in the temperature of $40^{\circ} \mathrm{C}$ was taken (Pabis et al., 1998); in case of SL2 a moisture content dependent water diffusion coefficient was used (Chu and Hustrulid, 1968); and in case of SL3 a moisture content dependent water diffusion coefficient, differentiated for the kernel components: germ, floury endosperm, horny endosperm and pericarp was taken for the simulations (Syarief et al., 1984).

The predicted values of the moisture content in dried maize kernels are presented in Fig. 5a, b.

The information about the local relative error of approximation for the numerical structural model for different values of the water diffusion coefficient is presented in 
a

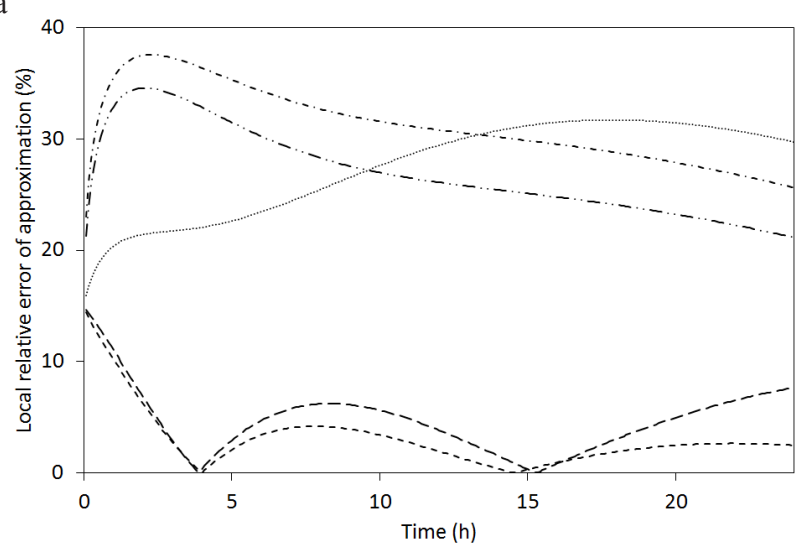

b

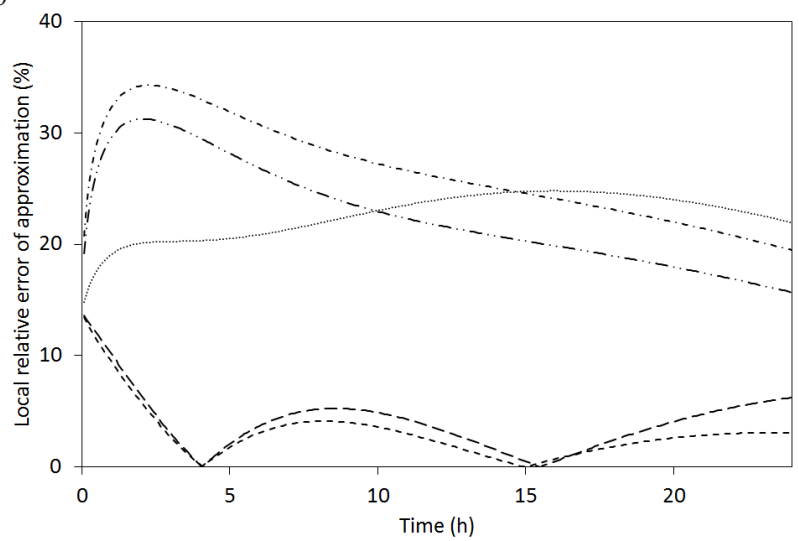

Fig. 6. The local relative error of approximation for predicting the moisture content inside corn kernels dried in a thin layer at the drying air temperature of $40^{\circ} \mathrm{C}$ and the relative humidity of: $\mathrm{a}-30$ and $\mathrm{b}-40 \%$ for 5 simulation variants. Explanations as on Fig. 5.

Fig. $6 a, b$. The uncertainties of the model measured by the global relative error of approximation for the relative humidity of $30 \%$ were: $6.82 \%$ for SI $1,5.87 \%$ for SI2, $25.08 \%$ for SL1, 32.72\% for SL2 and $29.05 \%$ for SL3. For the relative humidity of $40 \%$ they were: $5.96 \%$ for SI $1,5.32 \%$ for SI2, $21.46 \%$ for SL1, $28.70 \%$ for SL2 and $25.21 \%$ for SL3. It can be observed that the simulation results obtained with the use of the water diffusion coefficient estimated in the present study have significantly lower uncertainty when compared to simulation results obtained with the use of the values of this coefficient from the literature.

\section{CONCLUSIONS}

1. A method for computer-aided identification of the water diffusion coefficient in maize kernels dried in a thin layer was developed on the basis of laboratory measurements and original finite element inverse analysis. The method was exemplified for the drying air temperature of $40^{\circ} \mathrm{C}$ and relative humidity of 30 and $40 \%$.

2. Experimental data on moisture content changes in dried maize kernels were represented by the empirical formula and they were an input to the procedure of identi- fying the water diffusion coefficient. The uncertainty of this empirical formula measured by the global relative error of approximation was 1.31 and $1.16 \%$, respectively, for relative humidity of 30 and $40 \%$.

3 . The values of the water diffusion coefficient estimated on the basis of the developed method were used to enhance the numerical structural model and to predict more reliable moisture content distributions inside maize kernels during the whole process of thin-layer drying. The global relative error of approximation for the predicted moisture content results was between 5.32 and $6.82 \%$ for the estimated values of the water diffusion coefficient. In the case of the coefficient values taken from the literature this error was between 21.46 and $32.72 \%$.

4. The moisture content predictions corresponding to the water diffusion coefficient represented by the threeparameter empirical formula were characterized by lower values of the average global relative error of approximation compared to the predictions in which the two-parameter empirical formula was used, and the difference was $c a$. $0.8 \%$.

Conflict of interest: The Authors do not declare conflict of interest.

\section{REFERENCES}

Akpinar E.K., Bicer Y., and Yildiz C., 2003. Thin layer drying of red pepper. J. Food Eng., 59, 99-104.

ASABE Standards, 2009a. D245.6 OCT2007: Moisture relationships of plant-based agricultural products. ASABE, St. Joseph, MI, USA.

ASABE Standards, 2009b. S352.2 APR1988 (R2008): Moisture measurement - unground grain and seeds. ASABE, St. Joseph, MI, USA.

Babalis S.J., Papanicolaou E., Kyriakis N., and Belessiotis V.G., 2006. Evaluation of thin-layer drying models for describing drying kinetics of figs (Ficus carica). J. Food Eng., 75, 205-214

Chen G., Maier D.E., Campanella O.H., and Takhar P.S., 2009. Modeling of moisture diffusivities for components of yellow-dent corn kernels. J. Cereal Sci., 50(1), 82-90.

Chu S.-T. and Hustrulid A., 1968. General characteristics of variable diffusivity process and the dynamic equilibrium moisture content. Trans. ASAE, 11(5), 709-715.

Doymaz I. and Pala M., 2003. The thin-layer drying characteristics of corn. J. Food Eng., 60(2), 125-130.

Erbay Z. and Icier F., 2010. A review of thin layer drying of foods: theory, modeling, and experimental results. Critical Reviews in Food Sci. Nutrition, 50(5), 441-464.

Hacihafizoglu O., Kahveci K., Cihan A., and Akyol E., 2011. Finite element simulation of thin layer drying of corn. Proc. 9th WSEAS Int. Conf. Fluid Mechanics and Aerodynamics, WSEAS Press, Athens, Greece.

Jaros M., 1994. Error calculus in investigating drying processes. Part II. Error analysis in drying kinetics measurements (in Polish). Advances of Agricultural Sciences Problem Issues, 415, 303-311. 
Jaros M., Cenkowski S., Jayas D.S., and Pabis S., 1992. A method of determination of the diffusion coefficient based on kernel moisture content and its temperature. Drying Technol., 10(1), 213-222.

Jia C.C., Sun D.-W., and Cao C.W., 2000. Mathematical simulation of temperature and moisture fields within a grain kernel during drying. Drying Technol., 18(6), 1305-1325.

Kumar C., Karim A., Saha S.C., Joardder M.U.H., Brown R., and Biswas D., 2012. Multiphysics modelling of convective drying of food materials. Proc. Global Eng., Science and Technology Conference, Global Institute of Science and Technology, December 28-29, Dhaka, Bangladesh.

Muthukumarappan K. and Gunasekaran S., 2009. Modeling moisture diffusion in food grains during adsorption. In: Food Processing Operations Modeling. Design and Analysis (Eds S. Jun and J. Irudayaraj). CRC Press, Boca Raton, FL, USA.

Nemenyi M., Czaba I., Kovacs A., and Jani T., 2000. Investigation of simultaneous heat and mass transfer within the maize kernels during drying. Computers and Electronics Agriculture, 26(2), 123-135.

Olek W., Perré P., and Weres J., 2011. Implementation of a relaxation equilibrium term in the convective boundary condition for a better representation of the transient bound water diffusion in wood. Wood Sci. Technol., 45(4), 677-691.

Pabis S., Jayas D.S., and Cenkowski S., 1998. Grain drying. Theory and practice. Wiley Press, New York, NY, USA.

Perré P. and Turner I., 2007. Coupled heat and mass transfer. In: Fundamentals of Wood Drying (Ed. P. Perré), A.R.BO. LOR, Nancy, France.
Ranjan R., Irudayaraj J., and Jun S., 2001. Three-dimensional control volume approach to modeling heat and mass transfer in food materials. Trans. ASAE, 44(6), 1975-1982.

Suleiman R., Rosentrater K., and Bern C., 2013. Effects of deterioration parameters on storage of maize: a review. J. Natural Sciences Research, 3(9), 147-165.

Syarief A.M., Gustafson R.J., and Morey R.V., 1984. Moisture diffusion coefficients for yellow-dent corn components. ASAE Paper No. 84-355. ASAE, St. Joseph, MI, USA.

Weres J. and Jayas D.S., 1994. Effects of corn kernel properties on predictions of moisture transport in the thin-layer drying of corn. Trans. ASAE, 37(5), 1695-1705.

Weres J., Kiecana M., and Balcerzak K., 2014a. Two approaches to representing agri-food product geometry - an original software for constructing finite element models and the $3 \mathrm{ds}$ Max approach. J. Research Applications Agric. Eng., 59(1), 155-158.

Weres J., Olek W., Kujawa S., and Siatkowski M., $2014 b$. Integration of software components for determination and analysis of properties of agri-food and forest products. J. Research Applications in Agricultural Eng., 59(1), 159-163.

Weres J. and Olek W., 2005. Inverse finite element analysis of technological processes of heat and mass transport in agricultural and forest products. Drying Technol., 23(8), 1737-1750.

Weres J., Olek W., and Kujawa S., 2009. Comparison of optimization algorithms for inverse FEA of heat and mass transport in biomaterials. J. Theoretical Applied Mechanics, 47(3), 701-716. 